\title{
Analysis on Convergent Factors related to the Hopelessness of Health College Students
}

\author{
Hyun-Suk Lee ${ }^{1}$, Soomi Hong ${ }^{2}$ and Sang-Yun Bae ${ }^{3 *}$ \\ ${ }^{1}$ Dept. of Health Admin., Vision Univ. of Jeonju, Wansan-gu, Jeonju, Korea \\ ${ }^{2}$ Dept. of Health Admin., Vision Univ. of Jeonju, Wansan-gu, Jeonju, Korea \\ ${ }^{3}$ Dept. of Health Admin., Vision Univ. of Jeonju, Wansan-gu, Jeonju, Korea
}

Article History: Received:11 January 2021; Accepted: 27 February 2021; Published online: 5 April 2021

Abstract- This study investigates the convergence relationship of factors related to hopelessness among some health college students to identify the advantage of data analysis in the field of health care. The questionnaire was conducted using an unregistered self-administered questionnaire for 214 students from a college located in $\mathrm{J}$ area from October 1, 2018 to October 31, 2018. The hierarchical multiple regression analysis shows the following results. The hopelessness of respondents turned out to be significantly higher in following groups: a group in which academic burnout is higher, a group in which anxiety is higher, and a group in which psychosocial stress is higher. The results show explanatory power of $43.3 \%$. And this indicates that the efforts to decrease academic burnout, anxiety, and psychosocial stress are required to decrease hopelessness among health college students. These results can be used to guide college life counseling to lower hopelessness among health college students. It is also expected to be used for efficient data analysis of health problems. Further research requires the development of sophisticated data analysis techniques and procedures that can be used more efficiently in health care.

Keywords - Convergence, Health college student, Hopelessness, Academic burnout, Anxiety, Psychosocial stress

\section{INTRODUCTION}

The government and related agencies continue to make efforts to efficiently plan and implement policies to promote the health of local residents. In the health sector, the project's validity is verified by viewing the program's output as utility or effect rather than currency, so identifying cause and effect on health problems is an important means to improve the efficiency of health projects. A multidisciplinary cause of health-related problems requires a methodology to analyze data and explore causes through scientific methods. Therefore, this study identifies analysis in health care by measuring the variables of causes and results of health problems with a certified measure with proven reliability and validity and by utilizing statistical analysis tools such as t-test, ANOVA and hierarchical multiple regression analysis. As a health issue, the factors of the subject are academic burnout, anxiety, and psychosocial stress that affect the hopelessness of health college students. And the causal relationship of hopelessness and these factors was determined by statistical data analysis.

Hopelessness is the thought that one cannot change the negative future, and when it is prolonged, it appears to be an important psychological determinant that can lead to mental and physical disabilities[1][2]. Hopelessness is a predictor of the occurrence of a serious mental problem, and as hopelessness increases, the will to solve difficult problems which individuals are facing will decrease, and it will give rise to negative emotions such as cynicism and pessimism, eventually leading to a lower quality of life[3]. For that reason, it is necessary to interact with the environment surrounding individuals, and put efforts on lowering the level of hopelessness so that one may develop social adaptability to lead a healthy life.

When hopelessness persists for a long time, it seems that college students majoring in health science will lack the ability to plan ahead and tense up, which will lead to serious mental problems[4]. In terms of psychosocial health, hopelessness has been investigated as a factor affecting college students' physical, mental, social, family and academic activities in relation to the problem of internet addiction[5]. The hopelessness of college students was found to be positively correlated with sleep problems and interference with normal daily activities, and negatively correlated with adaptation to changes, patience and control, and positively correlated with thoughts of suicide. It was suggested that the effort to reduce college student's hopelessness could be a psychiatric intervention to prevent morbidity[6].

College students majoring in health science are under increasing pressure with regard to their academic and career path to acquire professional qualifications and secure job competitiveness due to innovative development in healthcare, and increased demand for high-quality job competency in hospitals[7]. In line with the trend of internationalization of medical services, support and provision of

*Corresponding Author- Sang-Yun Bae, Dept. of Health Admin., Vision Univ. of Jeonju, Wansan-gu, Jeonju, Korea 
more advanced practical English education to improve the ability to communication in foreign languages is also increasing the academic burden of college students in the health sector[8]. Excessive academic stress due to on-the-job training in hospitals and preparation for national exams can lead to mental problems such as depression, anxiety and valuelessness. However, there is a lack of voluntary efforts to overcome them, which can disrupt social life after graduation as well as in school, and there is a lack of social interest in them[9]. For college students majoring in health science, national exams for obtaining various qualifications and licenses, and working-level English lessons to improve the job competency for internationalized medical services may create a gap between an individual's career goals and reality, make it increasingly difficult to bridge the gap, create anxiety about reality, academic burnout, and daily stress, and increase hopelessness that thwarts any hope for the future.

College students' academic burden has a positive function of triggering academic wills and motivating them, but heavy academic pressure causes physical burnout, and academic burnout. And the students will experience the academic problem of learning incompetence. This can lead to psychological and emotional states such as maladjustment and tension, which can serve a negative function that causes anxiety[10][11]. College students' academic burnout and anxiety can cause cynicism and exhaustion in their studies, and also lead to a failure to adequately and flexibly respond to threatening objects that are not clearly recognized. As a result, they may manifest themselves as psychological and physical symptoms and increase psychosocial stress[4][9][11][13]. College students' academic burnout, anxiety and psychosocial stress may lead to mental and physical discomfort and defects, aggravating the state of hopelessness, i.e. decline in enthusiasm, a feeling of helplessness, an inappropriate response to reality and a failure to prepare for a changed future. It seems urgent to investigate related factors that can lower hopelessness.

In previous studies, the hopelessness of college students majoring in health science was reported to be related to emotional problems such as depression, helplessness and valuelessness[4][12][14], and the association between academic burnout and anxiety of college students was analyzed[10][11][15], and college students are said to experience psychosocial stress, i.e. being exposed to physical and mental pressure, in the absence of a response suitable for unclear objects and threatening situations[4][7][10]. The association between the psychosocial stress and hopelessness of youths was suggested[2], and it was suggested that college students' hopelessness was linked to psychosocial stress and to serious emotional and psychological problems[1][3][5]. Similar to this, existing studies suggest that it is possible to reduce anxiety, psychosocial stress and hopelessness by managing academic burnout, and to reduce the hopelessness of college students majoring in health science, it implies a two-track approach of intervention and management efforts to manage academic burnout, anxiety and psychosocial stress. Previous studies suggest that individual factors, such as academic burnout, anxiety and psychosocial stress, are related to hopelessness, but there are few studies that analyzed the convergent relationship among these factors in college students' hopelessness.

Therefore, the purpose of this study is to identify the advantages of data analysis in health care and to identify the convergent relationship among academic burnout, anxiety, psychosocial stress and hopelessness of college students majoring in health science. Also, this study will provide basic data that can be used for college life and academic counseling and guidance to reduce the hopelessness of college students majoring in health science who are faced with such problems as anxiety and psychosocial stress due to increased academic burden and increased demands for employment competitiveness. In addition, the analytical methodology presented in this study can be used to develop more efficient data analysis techniques and procedures that can be utilized in the health care field.

\section{ANALYSIS METHOD}

\subsection{ANALYSIS TARGET}

The $\mathrm{G}^{*}$ Power 3.1 program [16] was used to calculate the appropriate number of samples for analyzing factors related to hopelessness among health college students. In this program, significant levels of .05, effect size .15 and power .95 for t-test, ANOVA, and multi-regression analyses were calculated as critical F 1.68, and the minimum required number of samples was 208. The survey targets 300 people who exceed the appropriate number of samples calculated in case of poor response. At the randomly selected college located in $\mathrm{J}$ area, 300 randomly selected health college students were surveyed. The 241 questionnaires were retrieved $(80.3 \%)$ and the data were analyzed by 214 people, with the exception of the 27 poorly responded questionnaires. The survey period was from Oct. 1, 2018 to Oct. 31, 2018. We tried to keep the research ethics in the following ways. The surveyor visited the health department of the college and explained about the right to reject the questionnaire to the random person, the process of preparing the questionnaire, the protection of the data, and the purpose and contents of the survey. At this time, the self-registration questionnaire was distributed only to health college student who agreed to fill 
out the questionnaire. The documents were completed at the site under monitoring and retrieved immediately.

\subsection{ANALYSIS TOOL}

As shown in Table 1, The survey was conducted with 14 questions as general characteristics, 15 questions of academic burnout, 21 questions of anxiety, 18 questions of psychosocial stress and 20 questions of hopelessness. The academic burnout without cut off point was divided into low and high groups based on the median value and was compared with the hopelessness in t-test.

The general characteristics were gender, age(yrs), religious status, family life satisfaction, school record, relationships with friends, school life satisfaction, drinking status, smoking status, regular eating, regular exercise, daily average sleep time, hobbies and leisure activities, and subjective health status.

The scale for measuring academic burnout was based on the MBI-SS(Maslach Burnout InventoryStudent Survey) of Schaufeli et al., and the Korean version 15 items [18] that were adapted, modified and validated were used. This scale consists of five items of exhaustion, four items of cynicism and six items of inefficacy. The score is from 15 to 75 , and the higher the score, the higher the academic burnout. The Cronbach's $\alpha$ value, which is the internal reliability, was .902.

The scale for measuring anxiety was based on Beck et al.[19]'s Becky Anxiety Inventory (BAI), which was translated and validated using 21 questions [20][21]. The score is from 0 to 63, and the higher the score, the higher the anxiety. The Cronbach's $\alpha$ value, which is the internal reliability, was 922.

The psychosocial stress was based on GHQ(General Health Questionnaire)[22] and the PWISF(Psychosocial Well-being Index Short Form) was used as a scale that was reconstructed to fit the domestic situation and proved its validity. The score is from 0 to 54, and the higher the score, the higher the psychosocial stress. The total PWI score was divided into positive wellbeing group with 8 points or less, moderate distress group with 9 points or 26 points, and severe distress group with 27 points or more [23]. The hopelessness was compared in ANOVA. The Cronbach's $\alpha$ value, which is the internal reliability, was .907 .

The hopelessness was measured by using 20 items [25] of the hopelessness scale which was reconstructed based on the $\mathrm{BHOP}($ Beck Hopeness Scale)[24]. The score is from 0 to 20, and the higher the score, the higher the hopelessness. The Cronbach's $\alpha$ value, which is the internal reliability, was .884 .

TABLE I. The number of questions, range of score, cronbach' $\alpha$ and explanation of used scale

\begin{tabular}{|c|c|c|c|c|}
\hline $\begin{array}{l}\text { Scale } \\
\text { Sub-domains }\end{array}$ & $\begin{array}{l}\text { Number of } \\
\text { questions }\end{array}$ & $\begin{array}{c}\text { Range of } \\
\text { score }\end{array}$ & Cronbach' $\alpha$ & Explanation \\
\hline $\begin{array}{l}\text { Academic } \\
\text { burnout }\end{array}$ & 15 & $15-75$ & .902 & \multirow{4}{*}{$\begin{array}{c}\text { MBI-SS(Maslach Burnout Inventory-Student } \\
\text { Survey) }[15,16]\end{array}$} \\
\hline Exhaustion & 5 & & .899 & \\
\hline Cynicism & 4 & & .920 & \\
\hline Inefficacy & 6 & & .915 & \\
\hline Anxiety & 21 & $0-63$ & .922 & Becky Anxiety Inventory (BAI) $[17,18,19]$ \\
\hline $\begin{array}{l}\text { Psychosocial } \\
\text { stress }\end{array}$ & 18 & $0-54$ & .907 & $\begin{array}{l}\text { PWI-SF(Psychosocial Well-being Index Short } \\
\text { Form)[20,21] }\end{array}$ \\
\hline Hopelessness & 20 & $0-20$ & .884 & BHOP(Beck Hopeness Scale)[22,23] \\
\hline
\end{tabular}

\subsection{ANALYSIS PROCESSING}

The data were processed using IBM SPSS Statistics(ver 23.0). The comparison of the hopelessness according to general characteristics, academic burnout, anxiety and psychosocial stress of the subjects was verified by t-test and ANOVA. In order to categorize age(yrs) and daily average sleep time, which are variables that represent the general characteristics, age was divided into 21 years, the average daily sleep time was less than 7 hours, 7 to 8 hours, and more than 8 hours. To identify the control variables and independent variables affecting the hopelessness, hierarchical multiple regression analysis was conducted with variables that showed significant relationship in t-test and ANOVA as independent variables and hopelessness as dependent variables. At this time, family life satisfaction, school record, relationships with friends, school life satisfaction, drinking status, smoking status, regular eating, regular exercise, hobbies and leisure activities, and subjective health status, which are the control variables of 
categorical type that showed significant difference in the hopelessness, were converted into dummy variable. The significance level of hypothesis test was $p<.05$

\section{ANALYSIS RESULT}

\subsection{HOPELESSNESS BY GENERAL CHARACTERISTICS}

As shown in Table 2, the average hopelessness of the subjects was $5.13 \pm 4.75$ from 0 to 20 points, hopelessness by general characteristics was significantly higher for those with low age, unsatisfactory family life, poor school record, bad relationships with friends, unsatisfactory school life, and poor subjective health status. Other than that, gender, religion, drinking, smoking, regular meals, regular exercise, daily average sleep time, hobbies and leisure activities did not show significant difference with hopelessness.

Table 2. Hopelessness by General Characteristics

\begin{tabular}{|c|c|c|}
\hline \multirow{2}{*}{ Variables } & \multirow{2}{*}{$\mathbf{N}(\%)$} & \multirow{2}{*}{$\begin{array}{c}\text { Hopelessness(BHOP) } \\
\text { Mean } \pm \text { SD } \\
\end{array}$} \\
\hline & & \\
\hline \multicolumn{3}{|l|}{ Age(yrs) } \\
\hline$<21$ & $134(62.6)$ & $5.77 \pm 4.79$ \\
\hline $21 \leqq$ & $80(37.4)$ & $4.05 \pm 4.52$ \\
\hline $\mathrm{t}(\mathrm{p}$-value $)$ & & $2.593(.010)$ \\
\hline \multicolumn{3}{|l|}{ Family life satisfaction } \\
\hline Satisfied & 206(96.3) & $5.00 \pm 4.65$ \\
\hline Dissatisfied & $8(3.7)$ & $8.38 \pm 6.48$ \\
\hline $\mathrm{t}(\mathrm{p}$-value $)$ & & $-1.984(.049)$ \\
\hline \multicolumn{3}{|l|}{ School record } \\
\hline Good & $44(20.6)$ & $3.32 \pm 3.90$ \\
\hline Medium & $142(66.4)$ & $5.25 \pm 4.71$ \\
\hline Bad & $28(13.1)$ & $7.36 \pm 5.24$ \\
\hline $\mathrm{F}(\mathrm{p}$-value $)$ & & $6.649(.002)$ \\
\hline \multicolumn{3}{|c|}{ Relationship with the friend } \\
\hline Good & 201(93.9) & $4.94 \pm 4.61$ \\
\hline Bad & $13(6.1)$ & $8.90 \pm 6.24$ \\
\hline $\mathrm{t}(\mathrm{p}$-value $)$ & & $-2.606(.010)$ \\
\hline \multicolumn{3}{|l|}{ School life satisfaction } \\
\hline Satisfied & 187(87.4) & $4.60 \pm 4.49$ \\
\hline Dissatisfied & $27(12.6)$ & $8.78 \pm 4.99$ \\
\hline $\mathrm{t}(\mathrm{p}$-value $)$ & & $-4.456(<.001)$ \\
\hline \multicolumn{3}{|c|}{ Subjective health status } \\
\hline Good & $153(71.5)$ & $4.23 \pm 4.30$ \\
\hline Bad & $61(28.5)$ & $7.38 \pm 5.11$ \\
\hline $\mathrm{t}(\mathrm{p}$-value $)$ & & $-4.574(<.001)$ \\
\hline Total & $214(100.0)$ & $5.13 \pm 4.75$ \\
\hline
\end{tabular}

3.2. HOPELESSNESS BY ACADEMIC BURNOUT, ANXIETY AND PSYCHOSOCIAL STRESS

Table 3 compared the hopelessness of the subjects according to their academic burnout, anxiety and psychosocial stress. The group with high academic burnout had significantly higher hopelessness, and the group with high exhaustion, cynicism and inefficacy in the sub-areas had significantly higher scores. The group with high anxiety had significantly higher hopelessness, and the group with high psychosocial stress had significantly higher hopelessness.

Table 3. Hopelessness by Academic Burnout, Anxiety and Psychosocial Stress

\begin{tabular}{lcc}
\hline \hline Variables(Total score) & $\mathrm{N}(\%)$ & Hopelessness(BHOP) \\
\cline { 2 - 2 } & & Mean \pm SD \\
\hline
\end{tabular}

Total Academic burnout(MBI-SS) 


\begin{tabular}{|c|c|c|}
\hline Low group ${ }^{\S}$ & $104(48.6)$ & $3.09 \pm 3.54$ \\
\hline High group & $110(51.4)$ & $7.06 \pm 4.96$ \\
\hline t(p-value $)$ & & $-6.766(<.001)$ \\
\hline \multicolumn{3}{|l|}{ Exhaustion } \\
\hline Low group & $92(43.0)$ & $3.72 \pm 4.25$ \\
\hline High group & $122(57.0)$ & $6.19 \pm 4.85$ \\
\hline $\mathrm{t}(\mathrm{p}$-value $)$ & & $-3.888(<.001)$ \\
\hline \multicolumn{3}{|l|}{ Cynicism } \\
\hline Low group & $98(45.8)$ & $3.03 \pm 3.65$ \\
\hline High group & $116(54.2)$ & $6.90 \pm 4.87$ \\
\hline $\mathrm{t}(\mathrm{p}$-value $)$ & & $-6.472(<.001)$ \\
\hline \multicolumn{3}{|l|}{ Inefficacy } \\
\hline Low group & $107(50.0)$ & $3.32 \pm 3.73$ \\
\hline High group & $107(50.0)$ & $6.93 \pm 4.99$ \\
\hline $\mathrm{t}(\mathrm{p}$-value $)$ & & $-5.971(<.001)$ \\
\hline \multicolumn{3}{|l|}{ Anxiety(BAI)" } \\
\hline Normal & $195(91.1)$ & $4.79 \pm 4.55$ \\
\hline Mild anxiety & $8(3.7)$ & $7.50 \pm 5.16$ \\
\hline Moderate anxiety & $6(2.8)$ & $6.17 \pm 5.46$ \\
\hline Severe anxiety & $5(2.3)$ & $13.20 \pm 4.14$ \\
\hline F(p-value) & & $6.340(<.001)$ \\
\hline \multicolumn{3}{|c|}{ Psychosocial stress(PWI-SF) ${ }^{\mathbb{I}}$} \\
\hline Positive wellbeing & $22(10.3)$ & $1.55 \pm 3.19$ \\
\hline Moderate distress & $118(55.1)$ & $4.22 \pm 3.90$ \\
\hline Severe distress & $74(34.6)$ & $7.62 \pm 5.21$ \\
\hline $\mathrm{F}$ (p-value) & & $22.246(<.001)$ \\
\hline Total & $214(100.0)$ & $5.13 \pm 4.75$ \\
\hline
\end{tabular}

$\S$ : Low and high group classified by the median score of each variable.

II: Anxiety were divided into four groups, $\operatorname{normal}(<22$ of BAI score), mile anxiety $(22 \leqq$ BAI score $\leqq 26)$, moderate anxiety $(27 \leqq$ BAI score $\leqq 31)$ and severe anxiety $(32 \leqq$ of BAI score).

II : Psychosocial stress were divided into three groups, positive wellbeing ( $<9$ of PWI score), moderate distress $(9 \leqq$ PWI score $\leqq 26)$ and severe distress( $27 \leqq$ of PWI score).

\subsection{FACTOR TO INFLUENCE HOPELESSNESS}

In Table 4, hierarchical multiple regression analysis was conducted on four models to understand the explanatory power of independent variables on the hopelessness of the subjects.

Model I was found to have high hopelessness and explanatory power was $22.2 \%$ when the general characteristics were put into the regression model as age was lower, school record was worse, relationship with the friend was worse, school life satisfaction was lower, and subjective health status was worse. In Model II, as a result of putting academic burnout into the variables put into Model I, the higher cynicism and inefficacy, which are the sub-areas of academic burnout, the higher hopelessness, and $33.8 \%$ of hopelessness was explained as the variables put into Model II. In Model III, as a result of putting anxiety into variables put into Model II, the higher anxiety, the higher hopelessness, and variables put into Model III explained hopelessness by 40.1\%. In Model IV, as a result of putting psychosocial 
stress into variables put into Model III, the higher psychosocial stress, the higher hopelessness, and variables put into Model IV explained hopelessness by $43.3 \%$.

In the above model, academic burnout increased $11.6 \%$, anxiety increased $6.3 \%$, and psychosocial stress increased $3.2 \%$ of explanatory power. There was a high relationship in the order of academic burnout, anxiety and psychosocial stress in hopelessness. After reviewing the regression model, we found that the Durbin-Watson value was 1.929 , so there was no autocorrelation, and the Variance Inflation Factor value was from 1.067 to 1.989 , which was judged to be not multicollinearity.

Table 4. Hierarchial Multiple Regression of Selected Variables on Hopelessness

\begin{tabular}{|c|c|c|c|c|c|c|c|c|}
\hline \multirow{2}{*}{ Variables } & \multicolumn{2}{|c|}{ Model $\square$} & \multicolumn{2}{|c|}{ Model $\square$} & \multicolumn{2}{|c|}{ Model $\square$} & \multicolumn{2}{|c|}{ Model $\square$} \\
\hline & B & $\mathbf{t}$ & B & $\mathbf{t}$ & $\mathbf{B}$ & $\mathbf{t}$ & B & $\mathbf{t}$ \\
\hline Age(yrs) & -0.425 & $-2.484^{*}$ & -0.415 & $-2.576^{*}$ & -0.264 & -1.685 & -0.229 & -1.493 \\
\hline Family life satisfaction ${ }^{\S}$ & 2.108 & 1.303 & 1.694 & 1.121 & 0.81 & 0.557 & 0.849 & 0.599 \\
\hline School record ${ }^{\S}$ & 1.638 & $2.175^{*}$ & 0.112 & 0.149 & 0.32 & 0.447 & 0.347 & 0.497 \\
\hline Relationship with the friend ${ }^{\S}$ & 2.987 & $2.120^{*}$ & 3.147 & $2.385^{*}$ & 2.829 & $2.245^{*}$ & 2.661 & $2.164^{*}$ \\
\hline School life satisfaction ${ }^{\S}$ & 2.541 & $2.711^{* *}$ & 1.327 & 1.483 & 1.343 & 1.574 & 1.02 & 1.217 \\
\hline Subjective health status ${ }^{\S}$ & 2.583 & $3.936^{* *}$ & 1.892 & $3.006^{* *}$ & 1.068 & 1.706 & 0.662 & 1.064 \\
\hline $\begin{array}{l}\text { Academic Burnout(MBI-SS) } \\
\text { Exhaustion }\end{array}$ & & & 0.066 & 0.942 & -0.014 & -0.203 & -0.08 & -1.155 \\
\hline Cynicism & & & 0.184 & $2.063^{*}$ & 0.191 & $2.238^{*}$ & 0.162 & 1.943 \\
\hline Inefficacy & & & 0.254 & $3.720^{* * *}$ & 0.23 & $3.517^{* *}$ & 0.151 & $2.228^{*}$ \\
\hline Anxiety(BAI) & & & & & 0.157 & $4.616^{* *}$ & 0.13 & $3.819^{* *}$ \\
\hline Psychosocial stress(PWI-SF) & & & & & & & 0.124 & $3.376^{* *}$ \\
\hline Constant & 11. & 221 & 5.5 & & & 581 & & \\
\hline F & 9.8 & 51 & 11.5 & & 13 & 577 & 14 & 11 \\
\hline $\mathrm{R}^{2}$ & 0.2 & 22 & 0.3 & & & 101 & & \\
\hline $\mathrm{R}^{2}$ change & 0.2 & 22 & 0.1 & & & 63 & & \\
\hline Adjusted $\mathrm{R}^{2}$ & & 2 & 0.3 & & & 371 & & 02 \\
\hline
\end{tabular}

$\S:$ Dummy Variable, $*: \mathrm{p}<.05, * *: \mathrm{p}<.01$.

\section{CONSIDERATION}

This study attempted to analyze statistical data on factors related to hopelessness of health college students and to identify the advantages of data analysis in health care. The data analysis results are as follows. The average score of the hopelessness of the college students majoring in health science was $5.13 \pm 4.75$ from 0 to 20 points, which was higher than the average score of $4.57 \pm 4.58$ of the middle school students[2], suggesting that the academic burnout, anxiety and psychosocial stress of the health college students increased the hopelessness and that the hopelessness of the college students majoring in health science was a desperate problem in psychological and emotional mental health.

In general characteristics, the college students majoring in health science' hopelessness showed significant differences in age, family life satisfaction, school record, relationship with friends, school life satisfaction and subjective health status, but there was no difference in gender, religion, drinking, smoking, regular eating, regular exercise, daily average sleep time, hobby and leisure activities.

The results of the previous studies[4] that the female health college students had emotional difficulties in unsatisfactory family life group, poor school record group, bad relationship with friends group, unsatisfactory school life group, and poor subjective health status group were similar to those of college students majoring in health science. The analysis [10] that the gap between ideal and reality of college students is confirmed in age, family life satisfaction, school record, relationship with friends, school life satisfaction and subjective health status is similar in the hopelessness of college students majoring in health science. The point that women's depression level is high in gender was not confirmed in the hopelessness, which means that women are highly sensitive to the difference between reality and ideal, but attitude and will to change that they see their future negatively are not related to gender. When the result of the high hopelessness of the group with low age or low satisfaction with family life was seen, it was necessary to support and mediate resources to manage hopelessness considering age and home environment. The group with low school record, relationship with friends, and school life satisfaction 
showed high hopelessness, so the hopelessness of college students majoring in health science was considered to be effective in professional intervention by educational counseling guidance of college. Health is closely related to hopelessness of college students majoring in health science, so it was shown that the joint efforts of home and college will be effective in the health management to lower hopelessness.

Therefore, it was estimated that the development of counseling materials and active intervention to lower the hopelessness through the management of age, family life, school record, friendship, school life and health care of college students majoring in health science are required.

The results of this survey were similar to those of previous studies[10][11][15] on the relationship between academic burnout and hopelessness. The development of the health care field, the increase in job skills, the burden on academic and career[7], the strengthening of foreign language competence[8], the increasing academic burden[4] of the health-related curriculum, the cynicism and inefficacy of academic performance and the exhaustion of academic maladjustment seemed to be related to the hopelessness that weakens the will to change the future.

The point that the higher anxiety, the higher the hopelessness[7][10], was similar in the analysis of this survey, and the mental anxiety caused by inappropriate response to unclear objects and situations was linked to the hopelessness level. The lack of elastic defense against the dissonance of the surrounding environment caused psychological and physical symptoms, which were judged to increase the hopelessness of college students majoring in health science.

The correlation between psychosocial stress and hopelessness was confirmed in this study. Psychosocial stress caused by physical and mental pressure of college students majoring in health science was considered to be linked to hopelessness. It was estimated that the academic burden and anxiety due to the development and changing employment conditions of healthcare technology increased psychosocial stress and increased the hopelessness of college students majoring in health science.

Hierarchical multiple regression analysis was conducted to identify the explanatory power of independent variables affecting the hopelessness of college students majoring in health science. In the general characteristics of Model I, the lower age, the worse school record, the worse friendship, the lower school life satisfaction, the worse subjective health condition, and hopelessness was significantly higher. In the academic burnout of Model II, the higher cynicism and inefficacy, hopelessness was higher. In the psychosocial stress of Model IV, the higher psychosocial stress, hopelessness was higher, and the explanatory power of these variables was $43.3 \%$.

In particular, the explanatory power was increased by $11.6 \%$ for academic burnout, $6.3 \%$ for anxiety, and $3.2 \%$ for psychosocial stress, which showed that academic burnout was more related to hopelessness than psychosocial stress and anxiety. The college students majoring in health science' hopelessness was highly related to academic burnout, anxiety and psychosocial stress in order. In the existing survey of individual factors, the higher academic burnout[10][11][15], anxiety[7][10], psychosocial stress[1][3][5], the higher hopelessness, which was similar to this study. The relationship between psychosocial health status and hopelessness of college students in the humanities and natural sciences was similar in the college students majoring in health science.

The results of this survey suggest that it is necessary to manage academic burnout, anxiety and psychosocial stress as preventive factors in order to reduce the hopelessness of college students majoring in health science. In the case of academic burnout, counseling guidance that helps students to see their academic achievement positively, to achieve their academic goals in a planned and step-by-step manner, to increase their confidence, and to develop their will to resolve academic pressure can reduce the hopelessness of college students majoring in health science. It was shown that intervention efforts by experts who support the overcoming of psychological inconveniences such as unclear subjects and situation maladjustment and unfavorable tension could reduce the hopelessness of health college students. Also, it was considered that educational support to reduce stress that may cause physical and mental symptoms is necessary.

This study is based on a cross-sectional small sample of some college students majoring in health science at a specific point of time, so there is a limit to extend the results to the whole college students majoring in health science[26]. Also, the measurements of academic burnout, anxiety, psychosocial stress and hopelessness used in this survey analysis were conducted by the self-based method of the subjects, so it is not possible to exclude the risk of response bias. However, this study has significance in that it combined individual factors related to the hopelessness of college students majoring in health science to examine the relationship between academic burnout, anxiety, psychosocial stress and hopelessness. Further research requires the development of sophisticated data analysis techniques and procedures that can be used more efficiently in health care. We believe that analysis of various variables that can affect hopelessness for health college students with large sample sizes is necessary in further studies. We also 
believe that continuous investigation into negative or positive mental health problems such as depression, stress, and happiness that health college students may have is necessary[27]-[29].

\section{CONCLUSION}

This study analyzed the relationship among the academic burnout, anxiety, psychosocial stress and hopelessness of some college students majoring in health science to identify the advantages of data analysis in health care. The survey was conducted on 214 college students majoring in health science randomly selected from a college in $\mathrm{J}$ area from October 1, 2018 to October 31, 2018.

College students' hopelessness was significantly higher in the groups of lower ages, the groups dissatisfied with family life, the groups with poor school records, the groups with poor relationship with friends, the groups dissatisfied with school life, and the groups with poor subjective health. In the hierarchical multiple regression analysis, college students majoring in health science showed higher hopelessness when they had higher academic burnout, anxiety and psychosocial stress, and the explanation power of all these variables was $43.3 \%$.

Therefore, it is necessary to come up with a way to provide intervention and resources for the convergent factors of academic burnout, anxiety and psychosocial stress that affect hopelessness, and to use it for college life counseling and guidance to lower the hopelessness of college students majoring in health science. It is also expected to be used for efficient data analysis of health problems. Further research requires the development of efficient statistical analysis techniques and procedures for analyzing data in health care.

\section{REFERENCES}

1. Bae, Sang-Yun \& Cho, Young-Chae. "Analysis of The Influence of Hopelessness, Psychosocial Stress and Depression on Suicide Ideation among Middle School Students Using The Structural Equation Model." Journal of the Korea Academia-Industrial Cooperation Society 15.6(2014): 36853695.

2. Bela Mondal \& Sabyasachi Haldar, "Role of Academic Library to Encourage Student Community about the Impact of Yoga in Modern Age: An Overview", International Journal of Library Science and Research (IJLSR), Vol. 7, Issue 4, pp, 23-30

3. Bae, Sang-Yun, Yoon Hyun-Suk \& Cho, Young-Chae. "Factors Related to Suicide Ideation among Middle School Students." Journal of the Korea Academia-Industrial Cooperation Society 16.1 (2015): 544-554.

4. T. Aruna Bharathi, "A Study on the Self-Esteem Level among the Students of College of Home Science", International Journal of Educational Science and Research (IJESR), Vol. 7, Issue 5, pp, 7176

5. Kim, Min-Kyeong. "A Convergent Study of Variables Influencing on Suicide Ideation of Adolescents in Multicultural Family." Journal of the Korea Convergence Society 10.2(2019): 315324.

6. S. Ramesh, H. Samuel Thavaraj \& D. Ramkumar, "Impact of Emotional Intelligence on Academic Achievements of College Students - A Review", International Journal of Business Management \& Research (IJBMR), Vol. 6, Issue 2, pp , 25-30

7. Bae, Sang-Yun \& Kim, Seung-Hee. "Analysis of Convergent Influence of Positive Emotion, Negative Emotion and Job Seeking Stress on Depression among College Women of Health Affiliated Educations." Journal of Digital Convergence 14.3(2016): 269-278.

8. G. Sujatha, "Psychological Health of Teenagers with Reference to Intermediate Students", IMPACT: International Journal of Research in Humanities, Arts and Literature (IMPACT: IJRHAL), Vol. 6, Issue 4, pp, 199-210

9. Chung, Miyoung \& Cho, Ok-Hee. "Psycho-social Well-being of College Students Depending on A Level of Internet Addiction." The Journal of the Korea Contents Association 13.5 (2013): 366-376.

10. Jollie N. Alson, “Assesment of Students' Needs", International Journal of Humanities and Social Sciences (IJHSS), Vol. 6, Issue 1, pp; 25-32

11. Jung, Saim, Ju, Gawon, Lee, Sang Ick, Shin, Chul-Jin, Son, Jung-Woo, Kim, Siekyeong. "The Relationship between Insomnia and Suicidal Idea through Resilience." Korean Journal of Psychosomatic Medicine 25.2 (2017): 193-199.

12. Pankaj Sharma \& Sunil K Sharma, "Internet Addiction, Loneliness and Academic Performance Among the Secondary School Students", International Journal of Humanities and Social Sciences (IJHSS), Vol. 6, Issue 5, pp ; 19-24 
13. Lee, Hyun-Ju. "Convergence Differences of Academic Burnout, Career Preparation Behavior etc. by Resilience Clusters of Students Majoring in Medical Records." Journal of the Korea Convergence Society 8.4 (2017): 67-77.

14. Hong, Soomi \& Bae, Sang-Yun. "Convergence Factors Related with Communication Competency of Students in Health Majors in Studying for TOEIC." Journal of Digital Convergence 17.5 (2019): 257-266.

15. Kim, Seung-Hee \& Bae, Sang-Yun. "Analysis of Convergent Factors Related to Depression among Some College Women of Health Affiliated Educations." Journal of Digital Convergence 13.10 (2015): 367-375.

16. Lee, Hyun-Suk \& Bae, Sang-Yun. "Analysis of The Convergent Relationship between Stress Factors and Depression Levels in A College Students." Journal of Digital Convergence 17.4 (2019): 219-227.

17. Hong, Soomi, Kim, Seung-Hee \& Bae, Sang-Yun. "An Analysis on Structure Equation Model of Convergent Influence on Academic Burnout of Health Major Students in Studying for TOEIC." Journal of Digital Convergence 15. 7(2017): 329-342.

18. Kim, Seung-Hee \& Bae, Sang-Yun. "Analysis of Convergent Influence of Job Seeking Stress, Hopelessness and Depression on Childbirth Perception among Some College Women." Journal of Digital Convergence 14.9 (2016): 389-397.

19. Lee, Hyun-Suk \& Bae, Sang-Yun. "Influence of Stress, Self Factor and Emotional Factor on Smartphone Addiction Level among College Students." The Journal of the Korea Contents Association 17.5 (2017): 326-336.

20. Bae, Sang-Yun \& Kim, Seung-Hee. "Analysis of Convergent Influence of Self Esteem, Depression, Hopelessness, Locus of Control and Type A Behavior Pattern on Job Seeking Stress among Some College Women." Journal of Digital Convergence 14.12 (2016): 323-333.

21. Seo, Bo-Jun , Kim, Woo-Ho. "Converged Influence of The Academic Stress Recognized by Teenagers on Mental Health: Mediating Effect of Parent-child Communication." Journal of the Korea Convergence Society 8.7 (2017): 283-293.

22. Faul, Franz, Erdfelder, Edger, Lang, Albert-Georg \& Buchner, Axel. "G*Power 3: A Flexible Statistical Power Analysis Program for The Social, Behavioral, and Biomedical Sciences." Behavior Research Methods 39.2 (2007): 175-191.

23. Schaufeli, Wilmar B., Martínez, Isabel M., Pinto, Alexandra Marques, Salanova, Marisa \&, Bakker, Arnold B. "Burnout and Engagement in University Students: A Cross-national Study." Journal of Cross-Cultural Psychology 33.5 (2002): 464-481.

24. Shin, Hyojung, Puig, Ana, Lee, Jayoung, Lee, Ji Hee, Lee \& Lee, Sang Min. "Cultural Validation of The Maslach Burnout Inventory for Korean Students." Asia Pacific Education Review 12.4 (2011): 633-639.

25. Beck, Aaron T., Epstein, Norman, Brown, Gary \& Steer, Robert A. "An Inventory for Measuring Clinical Anxiety: Psychometric Properties." Journal of Consulting and Clinical Psychology 56. 6 (1988): 893-897.

26. Kwon, Seok-Man. Differential Roles of Dysfunctional Attitudes and Automatic Thoughts in Depression: An Integrated Cognitive Model of Depression, Ph D. Dissertation, University of Queensland, Australia, 1992.

27. Kwon, Seok-Man. Modern abnormal psychology, Seoul : Hakjisa, 2003.

28. Goldberg, David. Manual of The General Health Questionnaire, Windsor : NFER-Nelson, 1978.

29. Chang, Sei-Jin. Standardization of Collection and Measurement of Health Statistics Data, Seoul: The Korean Society for Preventive Medicine, 2000.

30. Beck, Aaron T., Weissman, Arlene, Lester, David \& Trexler, Larry. "The Measurement of Pessimism: The Hopelessness Scale." Journal of Consulting and Clinical psychology 42.6 (1974): 861-865.

31. Shin, Min Sup, Park, Kwang Bae, Oh, Kyung Ja \& Kim, Zoung Soul, "A Study of Suicidal Ideation among High School Students: The Structural Relation among Depression, Hopelessness, and Suicidal Ideation." The Korean Journal of Clinical Psychology 9.1 (1990): 1-19.

32. Lee Hyun-Suk, Hong Soomi \& Bae Sang-Yun. "Convergent Factors Related to the Hopelessness of some College Students Majoring in Health Science." Journal of Nursing Methodology, NADIA 1.1 (June 2020): 9-16.

33. Lee Ok-Ju. "Mediating Effects of Emotional Regulation on Depression and Life Satisfaction of College Students", Asia-pacific Journal of Convergent Research Interchange 6.2 (2020): 107-115.

34. Jung Seung-Ah. "Application of PWI-SF for Screening High-Risk Group of Mental Health among College Students", Asia-pacific Journal of Convergent Research Interchange 6.5 (2020): 49-60.

35. Kim Kyoungmi. "Perceived Stress and Happiness in College Students : On the Mediating Effects of Optimism and Flow", Asia-pacific Journal of Convergent Research Interchange 4.4 (2018): 81-92. 


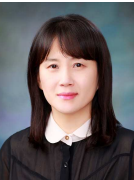

Lee, Hyun-Suk received the B.S. in food and nutrition from Sookmyung University, Seoul, in February 1990 She received the Master's degree in August 1995 and the Ph. D. in February 2012 in public health administration from Wonkwang University, Iksan. Since 2015, she has been an Assistant Professor with the Public Health Administration at Jeonju Vision University. Her research interests include Public Health Administration, health sciences and health education.

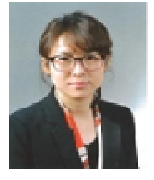

Hong, Soomi received the B.S. in public health from Purdue University, West Lafayette, IN, in 2003. She received the Master's degree in 2008 and the Ph.D. in 2016 in English Literature from Jeonju University, Jeonju. Since 2012, she has been an Associated Professor with the Public Health Administration at Jeonju Vision University. Her research interests include communication in English, health sciences and health education.

Bae, Sang-Yun received a master's degree in health from Chungnam National University's Graduate School of Health in February 2007 and the Ph.D. degree in health from Chungnam National University's Graduate School in February 2014. He has been a professor with the Public Health Administration at Jeonju Vision University since September 1996. His research interests include health sciences and health education. 